\title{
Aortic reconstruction with bovine pericardial grafts
}

\author{
Reconstrução aórtica com condutos de pericárdio bovino
}

Lindemberg Mota SILVEIRA, Orlando PETRUCCI JR., Pedro Paulo Martins de OLIVEIRA, Reinaldo Wilson

VIEIRA, Domingo Marcolino BRAILE

RBCCV 44205-615

\section{Abstract \\ Introduction: Glutaraldehyde-treated crimped bovine} pericardial grafts are currently used in aortic graft surgery. These conduits have become good options for these operations, available in different sizes and shapes and at a low cost.

Objective: To evaluate the results obtained with bovine pericardial grafts for aortic reconstruction, specially concerning late complications.

Method: Between January 1995 and January 2002, 57 patients underwent different types of aortic reconstruction operations using bovine pericardial grafts. A total of $29(50.8 \%)$ were operated on an urgent basis (mostly acute Stanford A dissection) and 28 electively. Thoracotomy was performed in three patients for descending aortic replacement (two patients) and aortoplasty with a patch in one. All remaining 54 underwent sternotomy, cardiopulmonary bypass and aortic resection. Deep hypothermia and total circulatory arrest was used in acute dissections and arch operations.

Results: Hospital mortality was $17.5 \%$. Follow-up was 24.09 months (18.5 to 29.8 months confidence interval) and complication-free actuarial survival curve was $\mathbf{9 2 . 3 \%}$ (standard deviation \pm 10.6 ). Two patients lately developed thoracoabdominal aneurysms following previous DeBakey II dissection and one died from endocarditis. One "patch" aortoplasty patient developed local descending aortic pseudoaneurysm 42 months after surgery. All other patients are asymptomatic and currently clinically evaluated with echocardiography and CT scans, showing no complications.

Conclusion: Use of bovine pericardial grafts in aortic reconstruction surgery is adequate and safe, with few complications related to the conduits.

Descriptors: Aorta, surgery. Aneurysm dissecting, surgery. Pericardium. Bioprosthesis.

\section{Resumo}

Introdução: Os condutos de pericárdio bovino corrugado, processados em glutaraldeído, têm sido cada vez mais utilizados em cirurgia cardíaca para reconstrução da aorta. Têm constituído alternativa ao uso de outros materiais, com custo aceitável e com grande disponibilidade de formas e tamanhos.

Objetivo: Analisar os resultados obtidos com o uso destes condutos de pericárdio bovino em operações de reconstrução aórtica, especialmente em relação a complicações tardias.

Método: Estudo retrospectivo com 57 pacientes operados entre Janeiro de 1995 e Janeiro de 2002 submetidos aa reconstrução aórtica com uso de condutos de pericárdio bovino. Destes, 29 (50,8\%) foram operados em condições de urgência

Work performed by the Cardiac Surgery Department of the Medical School of the State University of Campinas (UNICAMP)

- Cardiac Surgery Department - HC -FCM -UNICAMP.

Correspondence address:

Lindemberg Mota Silveira.

R. Coronel Quirino 1639, ap. 32.

Cambuí, Campinas,

SP, Brasil.

CEP: 13025-002.

E-mail: lindembergms@uol.com.br 
ou emergência (predominantemente dissecções agudas de aorta Stanford A) e 28 em situações eletivas. Cinqüenta e quatro pacientes foram submetidos a esternotomia e circulação extracorpórea com abordagem da aorta ascendente com parada circulatória total e hipotermia profunda nas dissecções agudas e nos aneurismas de arco aórtico. Em três pacientes foi realizada toracotomia, para troca da aorta descendente (dois pacientes) e aortoplastia com "patch" (um paciente).

Resultados: A mortalidade hospitalar foi de 17,5\%, sendo $\mathbf{7 \%}$ nos eletivos e $\mathbf{2 7 , 5 \%}$ nas urgências. O tempo de seguimento foi de $\mathbf{2 4 , 0 9}$ meses (intervalo de confiança 18,5:29,8 meses) e a sobrevida livre de complicações relacionadas aos condutos foi de $\mathbf{9 2 , 3 \%}$ (EP $\pm 10,6$ meses). Dois pacientes evoluíram com aneurisma tóraco-abdominal

\section{INTRODUCTION}

Glutaraldehyde-treated crimped bovine pericardial grafts have been widely used in cardiovascular surgery for aorta replacement surgeries. Their use is noteworthy in the intraoperative period for the ease of handling, good homeostatic characteristics, absence of the necessity of specific precoagulant treatment and low thrombogenicity [1,2]. Over the long term they have been demonstrated as having a low complication rate, including infections, thrombosis and bleeding [3]. Their low cost is also encouraging surgeons to use these grafts more frequently in this type of surgery.

The great availability of grafts of different sizes and shapes (e.g. aortic prostheses, valved tubes, etc.) has also assisted in the popularity of these materials for aorta replacement operations and their use in substituting synthetic materials such as Dacron [1]. The objective of this study is to analyze the immediate and long-term postoperative results after the use of different crimped bovine pericardial grafts in aorta replacement surgeries, with particular emphasis on the safety of the grafts and longterm complications.

\section{METHOD}

From January 1995 to January 2002, 57 patients underwent thoracic aorta replacement using crimped bovine pericardial grafts by the Cardiac Surgery Department of HC-UNICAMP, Brazil. The age of these patients varied from 25 to 74 years with a mean of 53.4 years ( $\mathrm{SD} \pm 11.9$ years). Of these patients extenso secundário à dissecção de aorta que se esxtendia até as artérias ilíacas e um faleceu por endocardite na evolução tardia. Um paciente submetido a aortoplastia em aorta descendente evoluiu 42 meses após com dilatação local, sendo reoperado. Todos os demais pacientes encontram-se assintomáticos e reavaliados periodicamente por métodos de imagem, sem apresentarem alterações.

Conclusões: $O$ resultado pós-operatório foi adequado com índices de sobrevida adequados e compatíveis com a literatura. O uso de condutos de pericárdio bovino em operações de reconstrução aórtica se mostrou exequiível e seguro, face ao baixo índice de complicações relacionadas ao material.

Descritores: Aorta, cirurgia. Aneurisma dissecante, cirurgia. Pericárdio. Bioprótese.

41 were male $(71.9 \%)$ and 16 female $(28.1 \%)$. The majority of the patients $(65 \%)$ were Caucasians.

The diseases of the operated patients were: acute Stamford A aortic dissections ( $\mathrm{n}=24)$, chronic Stamford A dissections $(n=10)$, ascending aortic aneurysms $(n=10)$, aortic ectatic-annulo dilations $(n=5)$, post-trauma descending aortic aneurysms $(n=3)$, ascending aorta rupture $(\mathrm{n}=1)$ (Figure 1) and one case of para-prosthetic failure. This latter patient had previously been submitted to Bentall's surgery in another hospital. In total, 28 patients underwent elective operations $(49.2 \%)$ and 29 urgent or emergency operations (50.8\%), among which $24(82.7 \%)$ were cases of acute Stamford A aortic dissections.

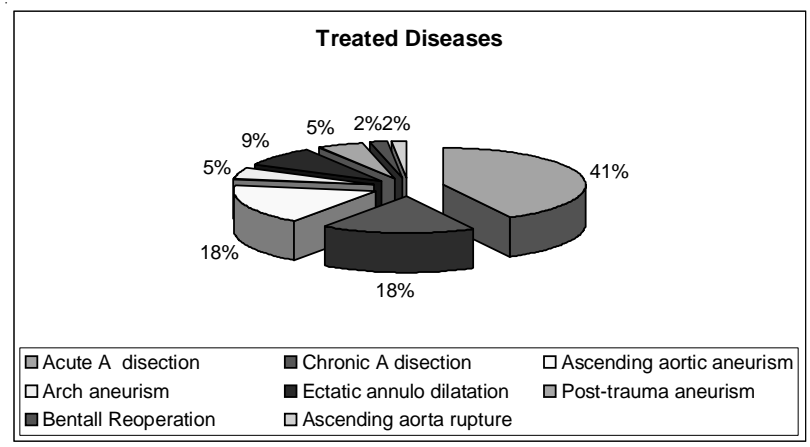

The majority of the patients underwent median sternotomies $(\mathrm{n}=54)$, systemic heparinization, bicaval venous catheterization and in all the cases of acute dissection or aortic arch disease, catheterization of the 
femoral or right subclavian arteries. These patients received deep hypothermia with a nasopharyngeal temperature of 18 ${ }^{\circ} \mathrm{C}$ and total circulatory arrest to treat the aorta artery and distal anastomosis was achieved by the open technique, at the end of which graft clamping and reestablishment of the cardiopulmonary bypass was made (Figures 2 and 3 ). During the period of total circulation arrest, retrograde brain perfusion at $200 \mathrm{~mL} / \mathrm{min}$ was received via the superior vena cava. The other patients suffered conventional aorta clamping. In all cases myocardial protection was achieved by retrograde normothermia sanguine micro-cardioplegia by the coronary sinus as of Braile.

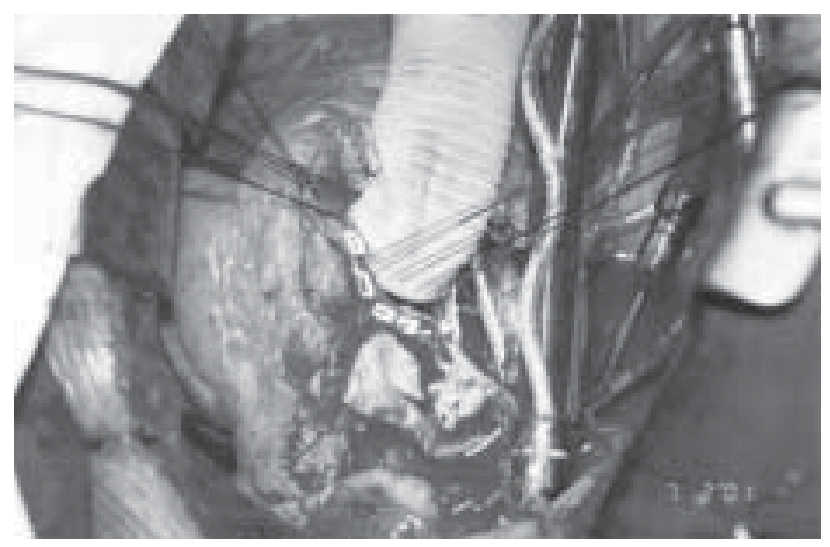

Fig. 2 - Use of bovine pericardium valved prosthesis in Bentall's surgery.

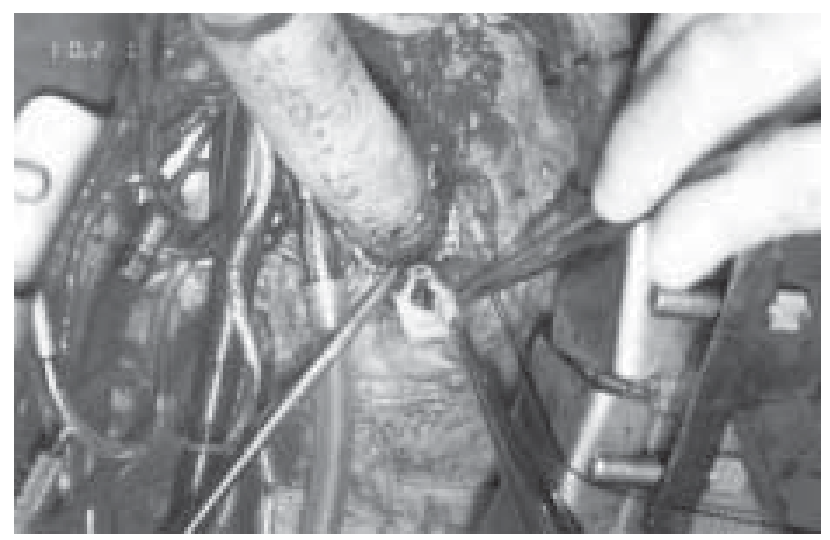

Fig. 3 - Use of bovine pericardium valved prosthesis in Bentall's surgery.

The following operations were performed by sternotomy: ascending aorta replacement with suspension of the cuspids of the aortic valve in the dissection cases $(n=22)$, Bentall's and De Bono's operations $(\mathrm{n}=18)$, ascending aorta replacement with aortic valve replacement $(n=9)$, David's operation ( $(\mathrm{n}=2)$, aortic valve reconstruction $(\mathrm{n}=2)$ and aortoplasty with patch $(\mathrm{n}=1)$ (Figure 4$)$. Coronary artery bypass grafting was concomitantly performed in three patients and replacement of the mitral valve in one.

\section{Performed surgeries}

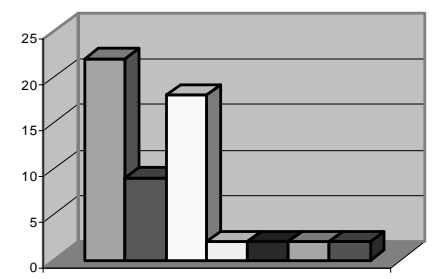

\begin{tabular}{|l|}
\hline Ascending aorta replacement \\
$\square$ Ascending aorta and valve replacement \\
$\square$ Bentall \\
$\square$ Descending aorta replacement \\
$\square$ Aortoplasty \\
$\square$ Aortic arch replacement \\
$\square$ Tirone operation \\
\hline
\end{tabular}

Fig. 4 - Performed surgeries

Three patients underwent broad left posterolateral thoracotomies to treat post-trauma descending aortic aneurysms. Two were submitted to prosthetic replacement of the descending aorta which was clamped and one was submitted to aortoplasty with patch, with left atrium-femoral cardiopulmonary bypass.

All patients received post-operative care in the intensive care unit and after, they were periodically clinically evaluated by transthoracic or transesophageal echocardiography and thoracic and abdominal computerized tomography. Statistical analysis was made using Kaplan-Meier survival curves.

\section{RESULTS}

The average follow-up time was 24.09 months (confidence interval 18.5 to 29.8 months). The global hospital mortality (up to 30 post-operative days) was 10 patients (17.5\%) five patients from bleeding due to coagulopathies, three from acute renal failure (ARF), one had respiratory failure and the other multiple organ failure.

Hospital mortality in patients operated in urgent or emergency conditions was eight of 29 patients (27.5\%) whilst in the elective cases the rate was only $7 \%$.

Of the 47 patients released from hospital, 32 (68\%) did not present with any type of early post-operative complications, whereas five presented with bleeding due to coagulopathies and required reoperations, three with ARF, 
two with pneumonia, two with mental confusion and two with sternal wound infections. All these patients totally recovered and were released from hospital in good clinical conditions and without any sequels even the two who presented with neurological alterations, soon after the operation.

The actuarial survival of all the operated patients was $78.3 \%$ (standard error (SE) \pm 14.8 months) with a follow-up of 70 months. The event free survival rate in respect to the graft was $92.3 \%$ (SE \pm 10.6 months) (Figure 5).

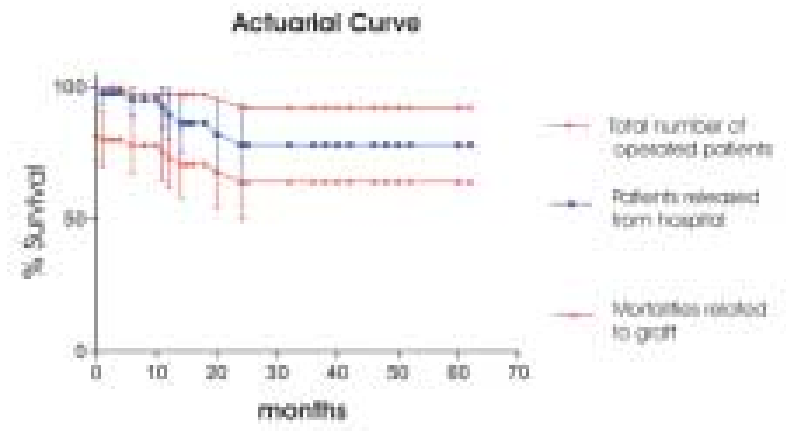

Fig. 5 - Acturial curve of patients' survival.

Among the 47 patients released from hospital, 38 (80.8\%) are asymptomatic or have CCI class I without any complications related to the operation or the bovine pericardial graft utilized. All were periodically examined clinically and by echocardiograph and computerized tomography (Figure 6).

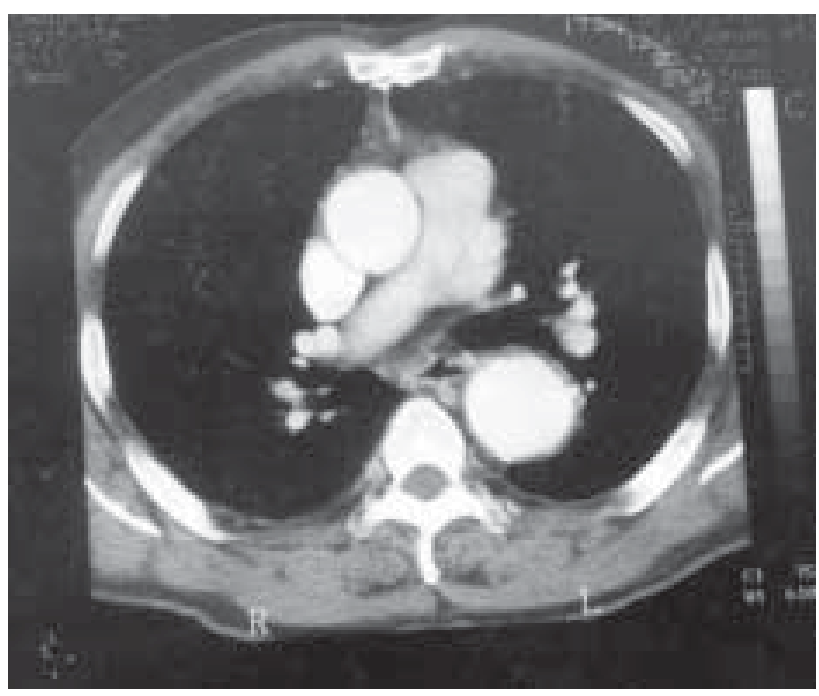

Fig. 6-Tomography 24 months after operation with good a result.

Another five patients were asymptomatic, but passed away for causes not related to the procedure (acute abdominal sepsis, renal complications from diabetes mellitus, hemorrhagic stroke and prostate neoplasm in two).
Two hypertensive patients with difficult control were reoperated, after 24 and 70 months for ascending aorta replacement due to extensive thoracic-abdominal aneurysms Crawford Type II, secondary to Stamford A dissection, which extended to the iliac arteries. Both patients died due to complications from the thoracic-abdominal aorta replacement operation. Neither of them presented with dilations or other complications at the site of the first surgery.

One patient submitted to Bentall's surgery for acute type A dissection, which evolved to ARF in the immediate postoperative period, was released from hospital in good conditions. This patient presented with vegetative endocarditis in the aortic prosthesis at six months after the operation, with death due to sepsis in another hospital without re-operation.

The patient who underwent aortoplasty with a patch in the descending aorta to correct a post-trauma pseudoaneurysm presented with sac-like dilation at the site of the patch diagnosed 42 months after the surgery (Figure 7). This patient was submitted to an endovascular stent implantation by the open technique and at 24 post-operative months from the second surgery no other complications have been evidenced.

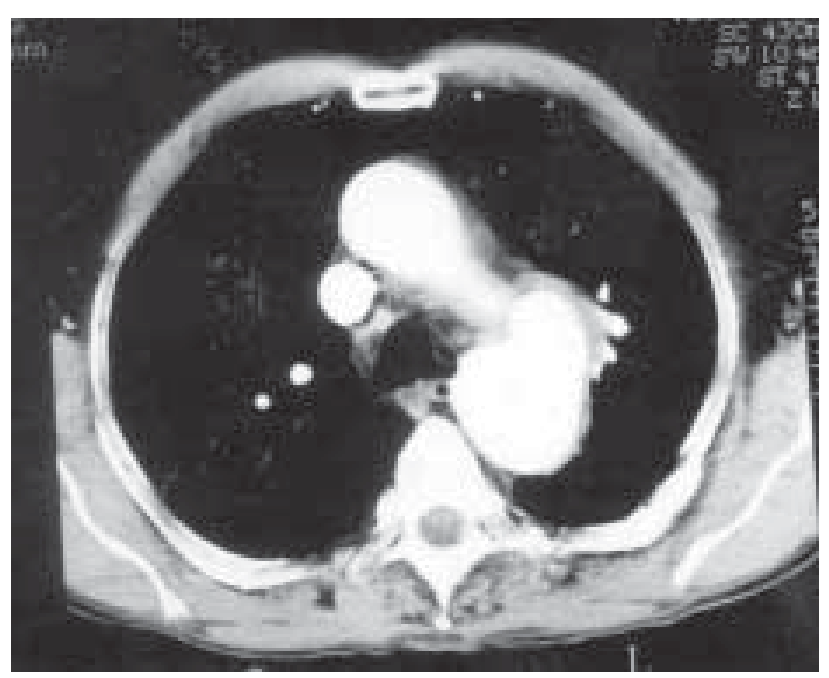

Fig. 7-Tomography of patient who evolved with descending aorta dilation 42 months after aortoplasty with patch.

\section{COMMENTS}

The first surgeries for the substitution of segments of the aorta artery were performed during in the 1940s, and constituted a true milestone in the development of aorta surgeries [4]. Gross et al. [5] are considered the pioneers of the modern era, utilizing homografts for the aorta correction. 
In 1951, Dubost et al. [6] described the use of homografts in the first successful replacement in the treatment of an abdominal aortic aneurysm. During this period, improvements were obtained by Cooley \& DeBakely [7] and with the advent of cardiopulmonary bypass, the treatment could be extended to the ascending aorta and the aortic arch.

Other developments such as the use of deep hypothermia, the utilization of total circulatory arrest and more efficient methods for myocardial and cerebral protection, improved the immediate and long-term results of the surgical procedure of these frequently challenging afflictions [8,9]. Among these developments is the use of man-made materials of synthetic fibers, which are making the aortic aneurysmal segment replacement the procedure of choice for this disease [10,11]. Currently, polyester fiber grafts, such as Dacron, impregnated with collagen or gelatins are widely used [12-14], with the aim of giving greater resistance to materials of low porosity to minimize the intra-operative bleeding. The use of these materials helped to diminish the mortality rates $[4,11,12]$.

Glutaraldehyde-treated bovine pericardium is one of the materials used. Bovine pericardium grafts constitute an attractive alternative to synthetic fibers resulting in an easy-to-use graft which is simple to handle especially during specific operative maneuvers, such as the reimplantation of coronary artery ostia [1]. Reports of the use of this material have been described throughout the world, stressing the practical nature of its intra-operative use and the few intra-operative complications related to bleeding [1,2]. Malashenkov et al. [3] described a series of 145 patients who used bovine pericardial grafts in aorta replacement, with complications related to the grafts in only four cases over the long-term.

Ardito et al. [2] in 1987 described the use of valved tubes of bovine pericardium in a Bentall surgery. Gontijo et al. [1] also cited their experience with bovine pericardial grafts in aorta surgery with a low rate of complications related to the grafts as well as a better homeostatic capacity in the intraoperative period when compared to Dacron. The low cost in comparison to synthetic fiber prosthesis has also been responsible for the greater use of bovine pericardial grafts.

In this study we demonstrated hospital mortality and morbidity rates comparable with other publications [1517]. In our casuistic, more than $50 \%$ of the patients were operated on in an urgent nature and they were submitted to deep hypothermia and total circulatory arrest. The nonlethal complications evidenced in these cases were those usually expected in this type of surgery. In particular a low prevalence of neurological complications was evidenced, with no patients being released from hospital with any type of sequel. The deaths, which occurred in the peri-operative period, were related to the treated disease and not the type of graft utilized. The authors consider bovine pericardial grafts very easy to use and with excellent homeostatic properties.

During the long-term follow-up, two patients died due to surgeries for thoracic-abdominal aneurysms. The development of these aneurysms occurred in two difficult to control hypertensive patients and who had been submitted to ascending aorta replacement and had an event-free post-operative evolution, but who had presented with dissection of the aorta artery to the iliac arteries, even at the first surgery. In spite of the bad evolution, there were no alterations in the bovine pericardial grafts in the ascending aorta as was later seen during the necropsy. These facts stress the importance of more intense monitoring in the long-term post-operative period of patients who initially present with similar lesions to these.

Considering that these two patients died due to the severity of the disease, only two patients had complications directly as a result of the material utilized. One patient developed with endocarditis, passing away in another hospital, and the other, who evolved with a saclike dilation at the location of the angioplasty, was reoperated by sternotomy and submitted to the implantation of an endovascular stent like an elephant's trunk with good results. The actuarial survival of $78.3 \%$ ( $\mathrm{SE} \pm 14.8$ months) and event-free survival of $92.3 \%$ ( $\mathrm{SE} \pm 10.6 \%$ ) were adequate and comparable to other publications.

Despite the average follow-up time being relatively short, the low rate of complications related to the material used encouraged the authors in relation to the use of bovine pericardial grafts. The absence of any complications such as the development of pseudoaneurysms at the site of the anastomosis with the bovine pericardial graft, development of fistulae or early calcification on the material were similar to published works. No patients evolved with alterations of an inflammatory nature caused by the material. Also the low cost of the material led the authors to consider the use of bovine pericardial grafts with a good cost-benefit relationship and possible adaptation for utilization in peripheral vascular surgery.

\section{CONCLUSION}

We conclude, therefore, that our casuistic presented with good results, both immediately after the surgery and in the long term, with a low rate of complications related to the bovine pericardial graft, which confirms the safety of this material. The facility of its utilization, the low occurrence of complications and the low cost of the material make bovine pericardium appropriate to be used as a graft in aorta replacement surgery. 


\section{BIBLIOGRAPHICREFERENCES}

1 Gontijo B, Vrandecic M, Fantini F, de Paula e Silva JA, Barbosa JT, Ferrufino AB et al.Gontijo B, Vrandecic M, Fantini $\mathrm{F}$ et al. - Replacement of the ascending aorta and aortic arch with bovine pericardial grafts. : A a preliminary report. Eur J Cardiothorac Surg 1995; 9:127132.

2 Ardito RV, Santos JLV, Mayorquim RC, Greco OT, Zaiantchic M, Soto HG et al. Substituição completa da aorta ascendente e da valva aórtica com tubo valvulado de pericárdio bovino. Rev Bras Cir Cardiovasc 1987; 2:129-38.

3 Malashenkov AI, Rusanov NI, Muratov RM, Movsesian RA, Fursov BA, Bykova VA et al. Eight years clinical experience with the replacement of the ascending aorta using composite xenopericardial conduit. Eur J Cardiothorac Surg 2000; 18:168-73.

4 Cooley DA. Aortic aneurysm operations: past, present and future. Ann Thorac Surg 1999; 67:1959-62, discussion 1979-80.

5 Gross RE, Hurwitt ES, Bill AH, Peirce EC.. Preliminary observation on the use of human arterial grafts in the treatment of certain cardiovascular defects. New Engl J Med 1948; 239:578-9.

6 Dubost C, Allary M, Oeconomos N. Resection of an aneurysm of the abdominal aorta: reestablishment of continuity by a preserved human arterial graft with result after five months. Arch Surg 1952; 64:405-8.

7 Cooley DA, DeBakey ME. Surgical considerations of intrathoracic aneurysms of the aorta and great vessels. Ann Surg 1952; 135:660-80.

8 Takamoto S, Matsuda T, Harada M, Shimamura Y, Miyata S. Simple hypothermic retrograde cerebral perfusion during aortic arch surgery. J Cardiovasc Surg 1992; 33:560-7.
9 Ueda Y, Miki S, Okita Y, Tahata T, Ogino H, Sakai T et al. Protective effect of continuous retrograde cerebral perfusion of the brain during deep hypothermic systemic circulatory arrest. J Card Surg 1994; 9:584-95.

10 Hufnagel CA. The use of rigid and flexible plastic prostheses for arterial replacement. Surgery 1955; 37:16574.

11 DeBakey ME, Jordan GL Jr, Beall AC Jrs. Basic biologic reactions to vascular grafts and prostheses. Surg Clin North Am 1965; 45:477-97.

12 Wukasch DC, Cooley DA, Bennett JG, Gontijo B, Bongiorno FP. Results of a new Meadox-Cooley double velour Dacron graft for arterial reconstruction. J Cardiovasc Surg 1979; 20:249-60.

13 Girardi LN, Talwalkar NG, Coselli JS.. Aortic root replacement: results using the St. Jude Medical/ Hemashield composite graft. Ann Thorac Surg 1997; 64:1032-5.

14 Vitale N, Owens WA, Hamilton JR, Forty J, Dark JH, Hasan A. Early results with Carbo-seal composite valve conduit for aortic root replacement. J Heart Valve Dis 1999; 8:80-4.

15 Crawford ES, Svensson LG, Coselli JS, Safi HJ, Hess KRs. Surgical treatment of aneurysm and/or dissection of the ascending aorta, transverse aortic arch, and ascending aorta and transverse aortic arch: factors influencing survival in 717 patients. J Thorac Cardiovasc Surg 1989; 98(5 Pt 1):659-74.

16 Heinemann M, Laas J, Jurmann M, Karck M, Borst HG. Surgery extended into the aortic arch in acute type A dissection: indications, techniques, and results. Circulation 1991; 84:III-25-30.

17 Bachet J, Brizard C, Goudot B, Dreyfus G, Teodori G, Brodaty D, et al. Repeated surgery for recurrent dissection of the aorta. Eur J Cardiothorac Surg 1990; 4:238-44. 